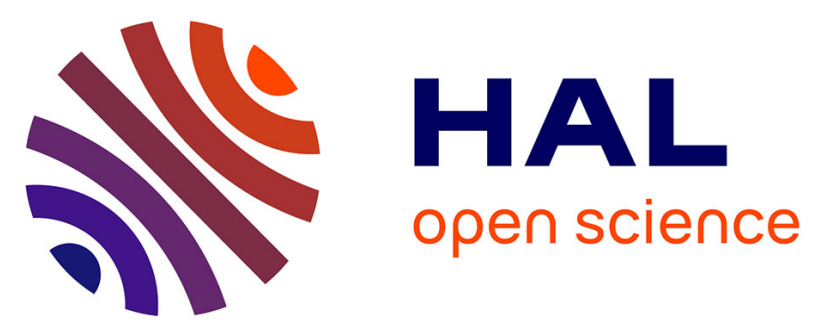

\title{
Vertebral strength prediction from Bi-Planar dual energy x-ray absorptiometry under anterior compressive force using a finite element model: An in vitro study
} Julie Choisne, Jean-Marc Valiadis, Christophe Travert, Sami Kolta, Christian Roux, Wafa Skalli

\section{To cite this version:}

Julie Choisne, Jean-Marc Valiadis, Christophe Travert, Sami Kolta, Christian Roux, et al.. Vertebral strength prediction from Bi-Planar dual energy x-ray absorptiometry under anterior compressive force using a finite element model: An in vitro study. Journal of the mechanical behavior of biomedical materials, 2018, 87, pp.190-196. 10.1016/j.jmbbm.2018.07.026 . hal-02493870

\section{HAL Id: hal-02493870 \\ https://hal.science/hal-02493870}

Submitted on 28 Feb 2020

HAL is a multi-disciplinary open access archive for the deposit and dissemination of scientific research documents, whether they are published or not. The documents may come from teaching and research institutions in France or abroad, or from public or private research centers.
L'archive ouverte pluridisciplinaire HAL, est destinée au dépôt et à la diffusion de documents scientifiques de niveau recherche, publiés ou non, émanant des établissements d'enseignement et de recherche français ou étrangers, des laboratoires publics ou privés. 


\title{
Vertebral strength prediction from Bi-Planar dual energy x-ray absorptiometry under anterior compressive force using a finite element model: An in vitro study
}

\author{
Julie Choisne ${ }^{\mathrm{a}, \mathrm{c}, *}$, Jean-Marc Valiadis ${ }^{\mathrm{a}}$, Christophe Travert ${ }^{\mathrm{a}}$, Sami Kolta ${ }^{\mathrm{b}}$, Christian Roux ${ }^{\mathrm{b}}$, \\ Wafa Skalli ${ }^{\mathrm{a}}$
}

a Arts et Metiers ParisTech, Institut de Biomecanique Humaine Georges Charpak, 151 bd de l'Hopital, 75013 Paris, France

b Cochin Hospital, Rheumatology Department, INSERMU1153, Paris Descartes University, Paris, France

${ }^{\mathrm{c}}$ Auckland Bioengineering Institute, University of Auckland, 70 Symonds street, 1010 Auckland, New Zealand

A R T I C L E I N F O

Keywords:

Osteoporosis

Vertebral strength

Bi-planar dual energy X-ray absorptiometry

Finite element model

Fracture

\begin{abstract}
A B S T R A C T
Finite element models (FEM) derived from qCT-scans were developed as a clinical tool to evaluate vertebral strength. However, the high dose, time and cost of qCT-scanner are limitations for routine osteoporotic diagnosis. A new approach considers using bi-planar dual energy (BP2E) X-rays absorptiometry to build vertebral FEM using synchronized sagittal and frontal plane radiographs. The purpose of this study was to compare the performance of the areal bone mineral density (aBMD) measured from DXA, qCT-based FEM and BP2E-based FEM in predicting experimental vertebral strength. Twenty eight vertebrae from eleven lumbar spine segments were imaged with qCT, DXA and BP2E X-rays before destructively tested in anterior compression. FEM were built based on qCT and BP2E images for each vertebra. Subject-specific FEM were built based on 1) the BP2E images using 3D reconstruction and volumetric BMD distribution estimation and 2) the qCT scans using slice by slice segmentation and voxel based calibration. Linear regression analysis was performed to find the best predictor for experimental vertebral strength $\left(\mathrm{F}_{\text {expe }}\right)$; aBMD, modeled vertebral strength and vertebral stiffness. Areal BMD was moderately correlated with $\mathrm{F}_{\text {expe }}\left(\mathrm{R}^{2}=0.74\right)$. FEM calculations of vertebral strength were highly to strongly correlated with $\mathrm{F}_{\text {expe }}\left(\mathrm{R}^{2}=0.84, \mathrm{p}<0.001\right.$ for BP2E model and $\mathrm{R}^{2}=0.95, \mathrm{p}<0.001$ for $\mathrm{qCT}$ model). The results of this study suggest that aBMD accounted for only $74 \%$ of $\mathrm{F}_{\text {expe }}$ variability while FE models accounted for at least $84 \%$. For anterior compressive loading on isolated vertebral bodies, simplistic loading condition aimed to replicate anterior wedge fractures, both FEM were good predictors of $\mathrm{F}_{\text {expe. Therefore FEM }}$ based on BP2E X-rays absorptiometry could be a good alternative to replace qCT-based models in the prediction of vertebral strength. However future work should investigate the performance of the BP2E-based model in vivo in discriminating patients with and without vertebral fracture in a prospective study.
\end{abstract}

\section{Introduction}

Osteoporosis is a bone disease which affects more than 1 in 3 women after their menopause and 1 of 10 men (McDonnell et al., 2007). The risk ${ }^{1}$ of bone fracture caused by osteoporosis is predominant at sites with a lot of trabecular bone such as the proximal femur, distal radius and vertebrae (Seeley et al., 1992). Vertebral fractures are one of the most common clinical manifestations with the major adverse consequences of osteoporosis as they usually occur under non-traumatic loading conditions. Height loss, back pain and functional disability are 
the most encountered consequences of vertebral fractures with repetitive fracture experience more likely occurring within a year after the first fracture (Wadsworth, 1990; Kanis and McCloskey, 1992). Early diagnosis of osteoporosis is therefore important for vertebral fracture prevention as drug treatments are more effective before perforation of the trabeculae (McDonnell et al., 2007; Parfitt, 1987). However difficulties for early diagnosis are associated with the asymptomatic behavior of vertebral osteoporosis as first fracture usually occurs before the patient presents for treatment (Kanis and McCloskey, 1992; Kanis et al., 2013). Diagnosis techniques determine bone mineral density (BMD) from dual energy X-ray absorptiometry (DXA) (Kanis et al., 2013; Kanis and Johnell, 2005) or from quantitative computed tomography (qCT) scans (Buckley et al., 2007). DXA is the most clinically used method to diagnose osteoporosis. However this technique can only predict $40-70 \%$ of vertebral fractures as it only measures areal BMD (aBMD) which does not account for three dimensional (3D) geometry and BMD distribution (Sornay-Rendu et al., 2005). Volumetric BMD (vBMD) can be determined from $\mathrm{qCT}$ scans but showed modest correlations $\left(\mathrm{R}^{2}\right.$ ranging from 0.17 to 0.75 ) to experimental vertebral strength (Buckley et al., 2007; Crawford et al., 2003; Singer et al., 1995; Edmondston et al., 1997; Ebbesen et al., 1999). Therefore the combination of patient-specific 3D geometry and vBMD distribution is necessary to predict vertebral strength. Finite element (FE) models derived from qCT images demonstrated good correlation $\left(\mathrm{R}^{2}=0.77-0.95\right)$ in the prediction of experimental vertebral strength (Buckley et al., 2007; Crawford et al., 2003; Dall'Ara et al., 2010; Chevalier et al., 2008; Imai et al., 2006). This technique contributed to analyze therapeutic treatments effects (Chevalier et al., 2010; Keaveny et al., 2007), improved vertebral fracture risk assessment in men in vivo (Wang et al., 2012) and provided an alternative clinical tool to DXA for patients with osteoporosis (Kopperdahl et al., 2014). However, the main limitations of such approach in routine osteoporotic diagnosis are the high radiation dose associated with high financial cost and time of qCT imaging technique. An alternative to the disadvantages of qCT imaging keeping 3D FE modeling of the spine is bi-planar dual energy (BP2E) X-rays absorptiometry from a low dose imaging system (Dubousset et al., 2010). Combined with 3D reconstruction technique of the spine (Humbert et al., 2009) for volumetric geometry and dual energy absorptiometry for volumetric BMD distribution, this technique allows for patient-specific FE model of the osteoporotic vertebra.

The purpose of this study was to compare the performance of the aBMD from DXA, qCT-based FE model and BP2E-based FE model in predicting experimental vertebral strength. The experimental set up allowed for anterior compression testing on isolated vertebral bodies to ensure repeatable loading condition simulating an anterior wedgeshape fracture.

\section{Material and method}

\subsection{Specimens}

Eleven lumbar spine segments (L1-L3) from cadaveric specimens were considered in this study ( 5 males and 6 females, age: 82 years \pm 7 ranging from 61 years to 87 years). Donors were fresh cadavers and no exclusion criteria was specified. Medical history was unveiled but all donors and vertebrae were screened by a trained clinician to ensure there was no evidence of former surgical procedures or spine conditions (e.g. spine curve deviation, suspicion of bone tumor tissue, compression or traumatic fracture). A total of 28 vertebrae were included ( $8 \mathrm{~L} 1,11$ L2 and 9 L3), after exclusion of vertebrae presenting anomalies.

\subsection{Data acquisition}

qCT scans of the lumbar spines were performed on a Scanner ICT 256 (Philips Healthcare, Cleveland, OH, USA) with the following settings; X-ray tube voltage and current: $120 \mathrm{kV}, 1489 \mathrm{~mA} / \mathrm{s}$, reconstruction matrix: $512 \times 512$, field of view: $250 \times 250 \mathrm{~mm}$ and a voxel size of $0.39 \times 0.39 \times 0.33 \mathrm{~mm}$. A calibration phantom (QRMESP, QRM GmbH, Germany) was used to map gray scale values to bone mineral density.

Dual energy X-ray absorptiometry (DXA) measurements were performed on a standard Hologic ${ }^{\circledR}$ QDR4500A (Hologic Inc, Waltham, MA, USA). The specimens were positioned in a $15 \mathrm{~cm}$ water bath and maintained with radio-transparent elastic bands. Bone mineral content (grams of hydroxyapatite equivalent), projected bone area $\left(\mathrm{cm}^{2}\right)$ and bone mineral density $\left(\mathrm{g} / \mathrm{cm}^{2}\right)$ were calculated for L1, L2 and L3 using the standard A-P scanning protocol. Scanner precision was quantified on 5 specimens with measurements repeated 3 times.

Low dose bi-planar dual energy (BP2E) X-rays absorptiometry were acquired for all spine segments using a dual energy prototype of the EOS $^{\circledast}$ system (EOS imaging, Paris, France) which can simultaneously take a pair of X-rays in the sagittal and frontal planes in upright position (Dubousset et al., 2010), allowing for 3D reconstruction of the spine (Humbert et al., 2009). Two levels of energy can be achieved with the EOS $^{\circledR}$ prototype by quickly changing the X-ray tube settings between two fast passes scans (approximately $20 \mathrm{~s}$ depending on the size of the lumbar spine). The computed projected areal Bone Mineral Density (aBMD) images of the vertebrae are similar to DXA images (Sapin et al., 2008; Sapin-De Brosses et al., 2012). aBMD measurement was previously validated by comparing EOS $^{\circledR}$ accuracy and reproducibility with the dual x-ray absorptiometry densitometers' characteristics (Sapin et al., 2008). X-ray tube voltage and current were $140 \mathrm{kV}$ and $149 \mathrm{~mA}$ for the high energy images and $70 \mathrm{kV}$ and $298 \mathrm{~mA}$ for the low energy images.

\subsection{Mechanical testing}

The 28 vertebrae were extracted from the spinal segment by cutting the intervertebral disc with a scalpel and disarticulating the posterior facets. The vertebrae were then cleaned from all soft tissue and the posterior elements were transected at the pedicles junction to the anterior body. The vertebral end plates were embedded in polymethyl methacrylate (PMMA) for parallelism to ensure uniform loading conditions. Anterior compressive tests were conducted using a quasi-static traction-compression Instron $5500 \mathrm{R}$ device (Instron Ltd., High Wycombe, UK) in combination with a $10 \mathrm{kN}$ load cell and a spherical seating loading platen (Instron Ltd., High Wycombe, UK) allowing for uniform load application onto the upper surface of the specimen (Fig. 1). The center of rotation of the spherical seating loading platen was aligned with the anterior third of the vertebral body to apply anterior compressive load to the vertebra. The anterior third of the vertebral body was measured using EOS $^{\circledR}$ radiographs of the vertebral body embedded in the PMMA layer before the destructive compression test. The specimen was bolted to the inferior test platen with the mold

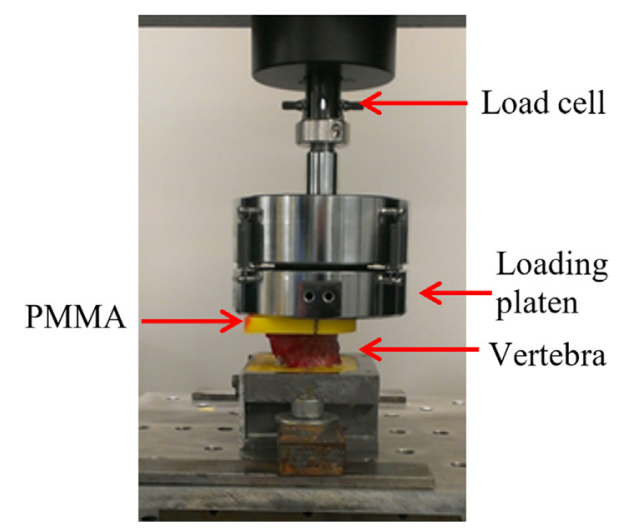

Fig. 1. Experimental setup for anterior compressive test of an isolated vertebral body. 


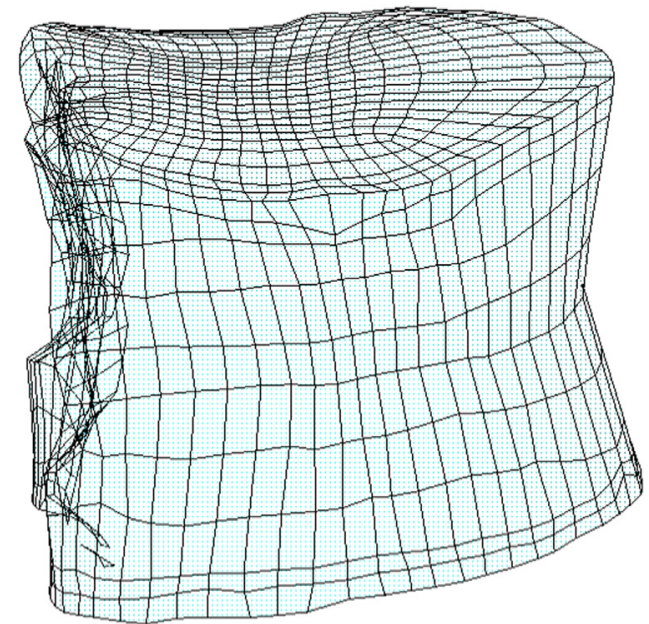

Fig. 2. Finite element model of a vertebral body. This model consisted of 8300 elements.

used for embedding the PMMA.

To avoid shear forces, the inferior test platen was mounted on an antero-posterior sliding connection and an initial compressive preload of $50 \mathrm{~N}$ was applied. Specimens were preconditioned by applying 10 cycles of compressive force between $100 \mathrm{~N}$ and $250 \mathrm{~N}$ at $0.1 \mathrm{~Hz}$ followed by destructive compression test at $1 \mathrm{~mm} / \mathrm{min}$ until ultimate force was achieved (Buckley et al., 2007). Experimental vertebral strength was defined as the ultimate load achieved and axial stiffness was calculated as the slope of the linear region of the force-displacement curve.

\subsection{Finite elements models}

A qCT-based finite element model was built from vertebral geometry obtained by a semi-automatic segmentation method (Le Pennec et al., 2014). A hexahedral mesh of the vertebral body (Fig. 2) was generated from this geometry using a multiblock meshing program wrote in C ++ (Grosland et al., 2009). Briefly, the multiblock meshing technique consists in multiple building blocks composed of meshing seeding arranged in rows, columns and layers. The mesh seeds are then projected on the vertebral surface and morphed to each vertebral surface as nodes to lay the foundation for the FE mesh (Grosland et al., 2009). In this 8304-element mesh the average element size was controlled to range between $1 \mathrm{~mm}$ and $1.5 \mathrm{~mm}$. All meshes were generated with the same topology for each vertebral level allowing the same element to be located approximately at the same position in the vertebra. Convergence analysis was performed to determine the ideal number of elements needed (Choisne et al., 2017).

Once the mesh generated, the average BMD of a single finite element was defined on the basis of the qCT scan voxels that fall inside the element. BMD value for each element was converted to linear elastic mechanical properties from an experimental relationship between BMD and elastic modulus (Choisne et al., 2017) as shown in Eq. (1). The Poisson ratio, $v$, was set to 0.4 (Imai et al., 2006).

$\mathrm{E}(\mathrm{MPa})=3230 \mathrm{BMD}\left(\mathrm{g} / \mathrm{cm}^{3}\right)-34.7$

A bi-planar dual energy X-rays absorptiometry based (BP2E-based) FE model was built from vertebral geometry obtained by 3D reconstruction of the spine from sagittal and frontal plane X-rays (Choisne et al., 2017). FE meshes similar to the qCT-based model were generated using the same element numbering and topology.

Volumetric BMD for each element was estimated from the lateral dual energy X-ray absorptiometry areal BMD image using a method previously described (Choisne et al., 2017). Shortly, a vBMD distribution based on the qCT density database was used to build a generic FEM model. Then, a digitally reconstructed radiography (virtual aBMD image) was made based on the generic model. Finally, an iterative vBMD adjustment was performed to maximize pixel similarity between the virtual and BP2E aBMD image. Once the image similarity was optimized, the personalized vBMD distribution from BP2E images was set. BMD values were then converted to material properties using the same Eq. (1) for each element.

\subsection{Boundary conditions}

Previously described boundary conditions and failure criterion (Sapin-De Brosses et al., 2012) were considered to build the qCT-based and BP2E-based FE models in order to reproduce the experimental testing procedure. Briefly, all models were virtually added layers of PMMA (about $0.5-1 \mathrm{~cm}$ thick, $\mathrm{E}=2500 \mathrm{MPa}, \nu=0.3$ ) to both vertebral endplates. Lower nodes of the lower PMMA layer were constrained in all degrees of freedom. Anterior compressive load was applied to the upper PMMA layer joined by rigid elements to a node located at the anterior third of the vertebra. Simulations were run on ANSYS software (ANSYS Inc., Canonsburg, PA, USA). Vertebral strength was defined when a contiguous region of $1 \mathrm{~mm}^{3}$ of elements reached $1.5 \%$ deformation (Sapin-De Brosses et al., 2012).

\subsection{Analysis}

Shapiro-Wilk tests were used to assess the normality of the distributions. Data were presented as the mean, standard deviation, and range. Linear regression analysis was performed to find the best predictor for experimental vertebral strength estimation; aBMD determined from DXA, modeled vertebral strength and vertebral stiffness. The Pearson determination coefficients of these regressions $\left(R^{2}\right)$ were calculated both in their raw and sample size-adjusted forms (adj. $R^{2}$ ). $\mathrm{R}^{2}$ values were statistically compared using Steiger's $\mathrm{Z}$ test for dependent samples (Meng et al., 1992). $P<0.05$ was considered the cut-off for significance in all statistical analyses.

\section{Results}

Descriptive data derived from the DXA analysis, finite element models analysis, and mechanical testing are summarized in Table 1.

According to patients classification criterion for DXA, eight specimens had osteoporosis with a t-score below -2.5 , one specimen had osteopenia and the two remaining specimen were considered normal (Assessment, 1994). The estimate of the 95\% confidence interval of the DXA's precision error was $0.010 \mathrm{~g} / \mathrm{cm}^{2}$. Bland and Altman plots, linear regression analysis coefficient of determination $\left(R^{2}\right)$, p-values, slope, intercept and standard error of the estimate (SEE) values are summarized in Table 2 and displayed in Figs. 3 and 4.

BMD measured from DXA was moderately related to experimental vertebral strength $\left(\mathrm{F}_{\text {expe }}\right)$. Experimental vertebral strength was better predicted by variables estimated from the FE models compared to aBMD measured from DXA as indicated by higher $\mathrm{R}^{2}$ and smaller standard errors of the estimate (Table 2).

Table 1

Descriptive statistics of 28 vertebrae.

\begin{tabular}{llll}
\hline & & Mean \pm SD & Range \\
\hline \multirow{2}{*}{ DXA } & T-score & $-2.7 \pm 1.4$ & $-5.1-0.7$ \\
& BMC $(\mathrm{g})$ & $10.19 \pm 3.88$ & $5.50-21.09$ \\
& BMD $(\mathrm{g} / \mathrm{cm} 2)$ & $0.724 \pm 0.182$ & $0.440-1.186$ \\
qCT-based FEM & Failure load (N) & $3067 \pm 1362$ & $1275-6331$ \\
& Stiffness (kN/mm) & $10,775 \pm 4332$ & $4998-19,358$ \\
BP2E-based FEM & Failure load (N) & $3033 \pm 1484$ & $995-6223$ \\
& Stiffness (kN/mm) & $11,103 \pm 4526$ & $4340-18,995$ \\
Mechanical testing & Failure load (N) & $3145 \pm 1573$ & $1270-6561$ \\
& Stiffness (kN/mm) & $5473 \pm 1892$ & $1643-8523$ \\
& & & \\
\hline
\end{tabular}


Table 2

Linear regression analysis between the experimental vertebral strength and the following variables: areal bone mineral density (aBMD) measured from DXA, qCT-based FEM strength $\left(\mathrm{F}_{\mathrm{qCT}}\right)$ and stiffness $\left(\mathrm{K}_{\mathrm{qCT}}\right)$, BP2E-based FEM strength $\left(\mathrm{F}_{\mathrm{BP} 2 \mathrm{E}}\right)$ and stiffness $\left(\mathrm{K}_{\mathrm{BP} 2 \mathrm{E}}\right)$ and experimental vertebral stiffness $\left(\mathrm{K}_{\text {expe }}\right)$.

$* \mathrm{p}<0.001$

The coefficient of determination for $\mathrm{F}_{\text {expe }} \mathrm{VS}$ aBMD was significantly lower than for $\mathrm{F}_{\text {expe }} \mathrm{VS} \mathrm{K}_{\text {expe }}$, $\left.\mathrm{p}<0.01\right), \mathrm{F}_{\mathrm{qCT}}(\mathrm{p}<0.01)$ and $\mathrm{K}_{\mathrm{qCT}}$ ( $p<0.05)$. qCT-based finite element model calculations of vertebral strength $\left(\mathrm{F}_{\mathrm{qCT}}\right)$ and stiffness $\left(\mathrm{K}_{\mathrm{qCT}}\right)$ were strongly correlated with $\mathrm{F}_{\text {expe }}$
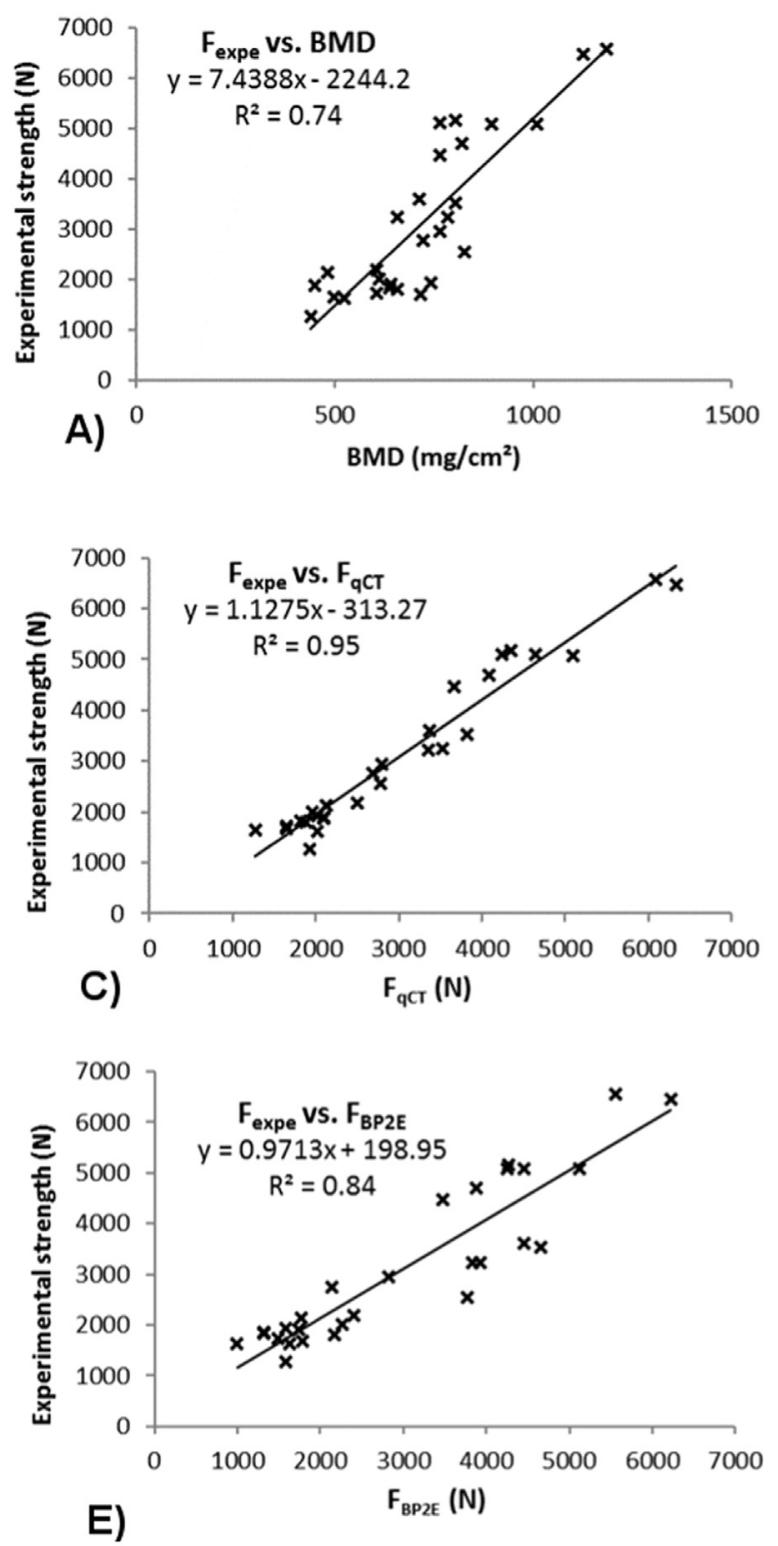

\begin{tabular}{lllll}
\hline & $\mathrm{R}^{2}$ & Slope & Intercept & SEE \% (N) \\
\hline $\mathrm{aBMD}\left(\mathrm{mg} / \mathrm{cm}^{2}\right)$ & $0.74^{*}$ & 7.44 & -2244 & $25(783)$ \\
$\mathrm{F}_{\mathrm{qCT}}(\mathrm{N})$ & $0.95^{*}$ & 1.13 & -313 & $11(333)$ \\
$\mathrm{F}_{\mathrm{BP2E}}(\mathrm{N})$ & $0.84^{*}$ & 0.97 & 199 & $20(617)$ \\
$\mathrm{K}_{\text {expe }}(\mathrm{kN} / \mathrm{mm})$ & $0.85^{*}$ & 0.77 & -1062 & $19(588)$ \\
$\mathrm{K}_{\mathrm{qCT}}(\mathrm{kN} / \mathrm{mm})$ & $0.92^{*}$ & 0.35 & -597 & $14(450)$ \\
$\mathrm{K}_{\mathrm{BP} 2 \mathrm{E}}(\mathrm{kN} / \mathrm{mm})$ & $0.78^{*}$ & 0.31 & -268 & $23(720)$ \\
\hline
\end{tabular}

$\left(\mathrm{R}^{2}=0.95, \mathrm{p}<0.001\right.$ and $\mathrm{R}^{2}=0.92, \mathrm{p}<0.001$ respectively). Statistical error in qCT-based model vertebral strength estimation was $78 \mathrm{~N} \pm 381$ compared to $\mathrm{F}_{\text {expe }}$ with a RMSE of $12 \%(382 \mathrm{~N})$ and a SEE of $11 \%(333 \mathrm{~N})$. BP2E-based FE model vertebral strength $\left(\mathrm{F}_{\mathrm{BP} 2 \mathrm{E}}\right)$ and stiffness $\left(\mathrm{K}_{\mathrm{BP} 2 \mathrm{E}}\right)$ determination were highly correlated with $\mathrm{F}_{\text {expe }}\left(\mathrm{R}^{2}\right.$ $=0.84, \mathrm{p}<0.001$ for $\mathrm{F}_{\mathrm{BP} 2 \mathrm{E}}$ and $\mathrm{R}^{2}=0.78, \mathrm{p}<0.001$ for $\mathrm{K}_{\mathrm{BP} 2 \mathrm{E}}$ ) and $\mathrm{F}_{\mathrm{qCT}}\left(\mathrm{R}^{2}=0.90, \mathrm{p}<0.001\right.$ for $\mathrm{F}_{\mathrm{BP} 2 \mathrm{E}}$ and $\mathrm{R}^{2}=0.83, \mathrm{p}<0.001$ for $\mathrm{K}_{\mathrm{BP} 2 \mathrm{E}}$ ). Statistical error in for $\mathrm{F}_{\mathrm{BP} 2 \mathrm{E}}$ estimation was $112 \mathrm{~N} \pm 629$ compared to $\mathrm{F}_{\text {expe }}$ with a RMSE of $20 \%(628 \mathrm{~N})$ and a SEE of $20 \%$ $(617 \mathrm{~N})$.

\section{Discussion}

The purpose of this study was to compare the performance of the aBMD from DXA, qCT-based FEM and the bi-planar dual energy X-rays absorptiometry based (BP2E-based) FEM in predicting experimental vertebral strength.

The results of this study suggest that FE models are better
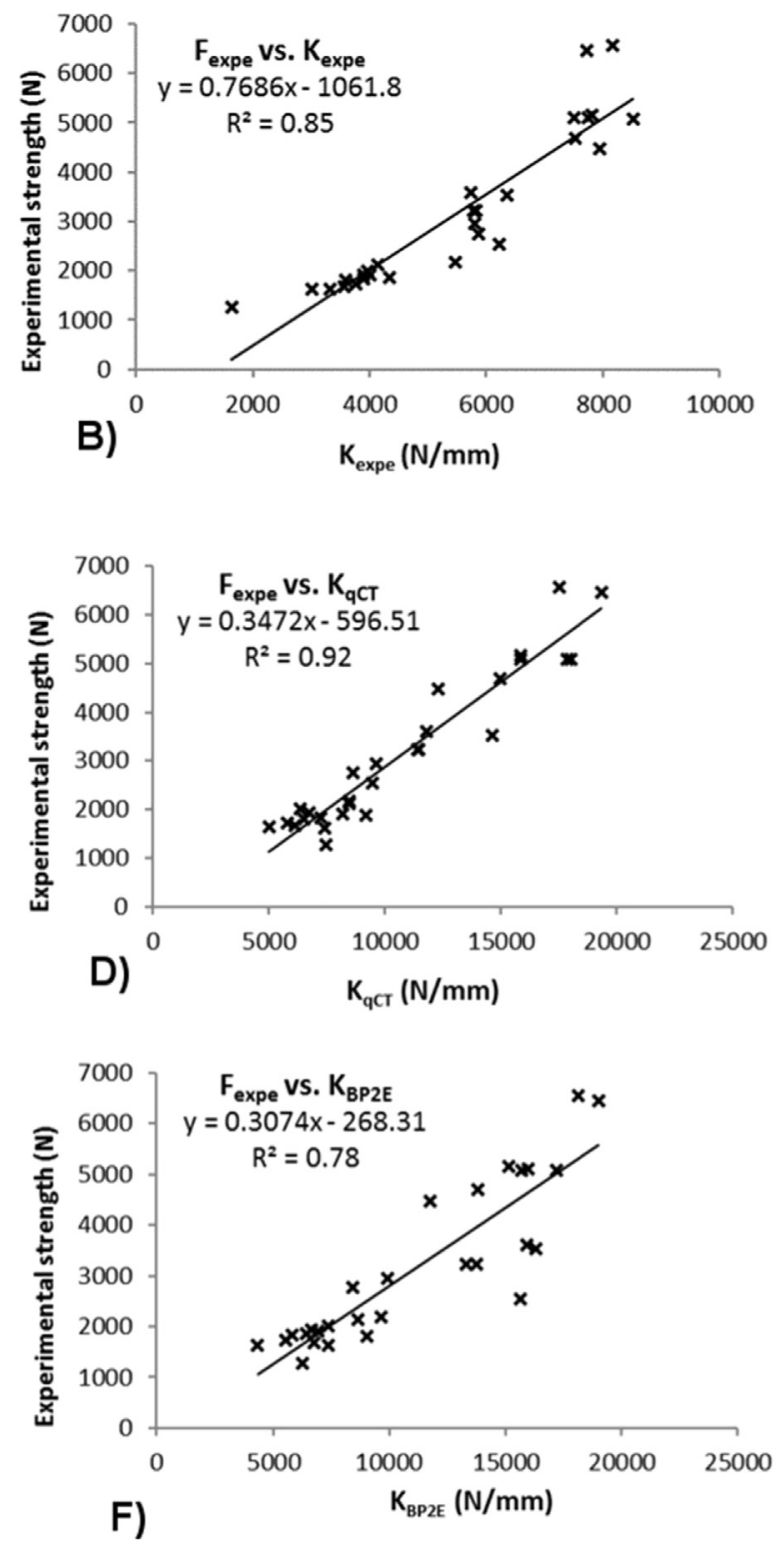

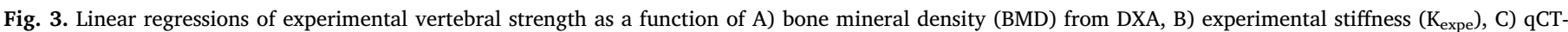

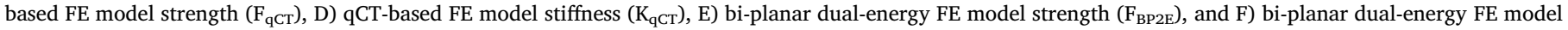
stiffness $\left(\mathrm{K}_{\mathrm{BP} 2 \mathrm{E}}\right)$. 

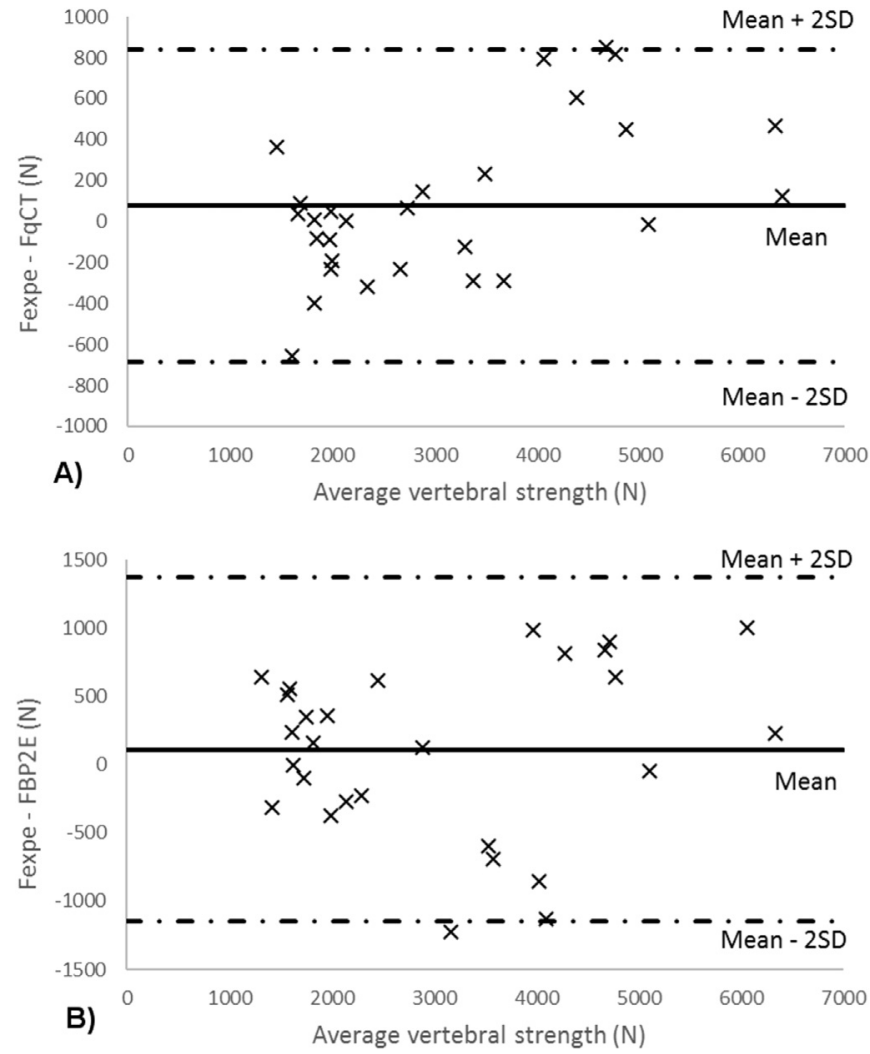

Fig. 4. Bland and Altman plots between experimental vertebral strength and vertebral strength determined from A) FE-based $\mathrm{qCT}\left(\mathrm{F}_{\mathrm{qCT}}\right)$ and $\left.\mathrm{B}\right)$ FE-based BP2E $\left(\mathrm{F}_{\mathrm{BP} 2 \mathrm{E}}\right)$.

experimental vertebral strength predictors than aBMD measured with DXA. For anterior compressive loading on isolated vertebral bodies, simplified loading condition applied at the anterior third of the vertebra, aBMD accounted for $74 \%$ of the variability in experimental vertebral strength while FE models accounted for at least $84 \%$ of the strength variability. This $10 \%$ difference is clinically relevant as it can diagnose osteopenia bone earlier compared to DXA that can mostly distinguish between healthy and very osteoporotic bone.

\section{1. $B M D$ from $D X A$}

BMD from DXA was the worst predictor for experimental compressive vertebral strength with a coefficient of determination of 0.74 and SEE of $25 \%$. Previous studies showed similar correlation ranging from 0.46 to 0.69 between aBMD and experimental ultimate compressive load (Edmondston et al., 1997; Chevalier et al., 2008; Faulkner et al., 1991; Eriksson et al., 1989; Moro et al., 1995; Roux et al., 2010). PA-projection DXA is the method of choice to diagnose osteoporosis, however BMD measurement was shown to account for less than $75 \%$ of vertebral strength variability in vitro. Moreover in vitro DXA measurements are not influenced by extra-vertebral tissues and might therefore appear to have higher accuracy than DXA when performed in vivo (Ebbesen et al., 1999). Furthermore, an in vivo study aiming to prospectively assess the risk of new clinical vertebral fractures demonstrated that DXA measurement hazard ratio change between fracture and non-fracture for aBMD was significantly lower than for strength determined from finite element models based on qCT images (Wang et al., 2012).

\section{2. qCT-based finite element model}

Vertebral strength determined from qCT-based FE model was the best predictor for experimental vertebral strength with a coefficient of determination of 0.95 and SEE of $11 \%$. These results are in agreement with the literature regarding the efficacy of FE models to predict experimental vertebral strength with $\mathrm{R}^{2}$ value ranging from 0.77 to 0.95 . Moreover this model was a good predictor of bone elastic behavior with model stiffness highly correlated to experimental stiffness $\left(R^{2}=0.86\right)$. Compared to existing FE models (Buckley et al., 2007; Crawford et al., 2003; Chevalier et al., 2008; Imai et al., 2006; Liebschner et al., 2003), this model was tested in a configuration replicating anterior wedge fractures, commonly seen on osteoporotic patients, by applying anterior compression on the vertebral body instead of centered compression. One study (Dall'Ara et al., 2010) used a similar mechanical setup by including a loading plate with a ball joint to allow for rotation and therefore creating anterior wedge fractures. Using a non-linear finite element model, they estimated experimental vertebral strength and stiffness with coefficients of determination of 0.79 and 0.49 . The present study showed higher correlation with experimental output using a simplified linear FE model in a more time efficient manner, although our model is less adapted to determine fracture detailed mechanism oppositely to the nonlinear FE model (Dall'Ara et al., 2010).

\subsection{BP2E based finite element model}

BP2E-based model output was a good predictor for experimental vertebral strength and stiffness with coefficient of determination of 0.84 and 0.78 respectively. This model using bi-planar dual energy X-rays absorptiometry (BP2E) performed as good as existing FE models based on qCT images (Buckley et al., 2007; Crawford et al., 2003; Dall'Ara et al., 2010; Chevalier et al., 2008; Imai et al., 2006; Liebschner et al., 2003). Compared to the present qCT-based FE model, the coefficient of determination between BP2E-based model and experimental vertebral strength was statistically lower $(\mathrm{p}<0.05)$ but with a slope closer to one (0.97 for BP2E vs 1.13 for qCT) and intercept approaching 0 (199 for BP2E vs -313 for qCT). Both models were highly correlated with $\mathrm{R}^{2}$ $=0.90$ for vertebral strength and 0.83 for stiffness. FE models based on BP2E X-rays absorptiometry could become a good alternative to replace qCT-based model in the prediction of vertebral strength avoiding qCT scan disadvantages such as high cost and radiation exposure. Indeed the $\operatorname{EOS}^{\circledR}$ device is a low dose X-ray system with a fast acquisition time and an effective dose received of $\sim 0.3 \mathrm{mSv}$ (Damet et al., 2014) compared to $5 \mathrm{mSv}$ with qCT scan (Wang et al., 2012). Lateral and AP projection DXA images could be used with the same approach keeping in mind that DXA images resolution is low (Sapin et al., 2008; Ahmad et al., 2010; Whitmarsh et al., 2011, 2013).

\subsection{Potential clinical applications}

This study shows improved prediction in the vertebral strength assessed experimentally by using FE models compared to DXA, the most clinically used method to detect osteoporosis. Moreover this study highlights potential clinical applications of BP2E-based FE models and the advantages of using FE models rather than DXA in the diagnosis of osteoporosis. Further, these findings support those of previous studies showing that vertebral FE models are better predictors for experimental vertebral strength than BMD measurements alone (Buckley et al., 2007; Crawford et al., 2003).

If bi-planar dual energy (BP2E) X-rays absorptiometry performs as well in vivo as it did ex vivo, BP2E-based FE model could potentially become an alternative to qCT-based models involving high cost and radiation exposures. Due to $\mathrm{qCT}$ scan disadvantages most clinicians prefer using less irradiant methods such as DXA instead of qCT images in the diagnosis of osteoporosis (Kanis et al., 2013). The present study demonstrated that BP2E-based FE model is a better predictor for experimental vertebral strength than DXA ex vivo. A previous study demonstrated that the $\operatorname{EOS}^{\circledR}$ system has a good diagnostic value for the diagnosis of vertebral fracture with a better legibility of upper thoracic 
spine than DXA in vivo (Briot et al., 2015). With its low radiation dose and cost, the $\mathrm{EOS}^{\circledR}$ system is a potential useful technique in the diagnosis of osteoporosis. However, it will be important to undertake prospective studies to determine the predictive strength of BP2E-based model for vertebral fracture risk assessment before the clinical benefit can be judged. While the vertebral strength prediction of the FE method used in this study is good for ex vivo condition, precision for in vivo applications is likely to be more variable. Factors influencing in vivo measurements are the soft tissue heterogeneity surrounding the lumbar spine, the variability of in vivo positioning and the greater soft tissue volume X-ray absorption. Nonetheless, most of these factors can be controlled using the sagittal and frontal views to assess soft tissue heterogeneity and include it in the calculation of soft tissue attenuation. Variability in patient positioning should not be an issue for 3D reconstruction as the method demonstrated a position precision of maximum $2.1 \mathrm{~mm}$ error on spine with severe scoliosis (Cobb's angle $>30^{\circ}$ ) (Humbert et al., 2009). Moreover the volumetric BMD distribution method takes into account axial rotation as long as the posterior arch does not superimpose the vertebral body on the lateral view, which will automatically overestimate the vBMD distribution as the posterior arch is significantly denser than the vertebral body (Travert et al., 2013). Future work will assess the performance of the BP2E-based FE model in discriminating patients with and without vertebral fracture in a prospective study.

The present study has several limitations to be considered. Possible error sources were the accuracy of the $3 \mathrm{D}$ reconstruction, which can affect the vertebral body volume and thus the apparent density, the contribution of the cortical bone layer and, to a lesser extent, the surrounding soft tissues. However, spine 3D reconstruction position precision was quantified to be less than $1.8 \mathrm{~mm}$ which should not affect average vBMD distribution (Humbert et al., 2009). Moreover, aBMD accuracy of the EOS $^{\circledR}$ system was determined to be below 5.2 per cent, versus 7.2 per cent for a DXA system in the same conditions (Sapin et al., 2008). Cortical shell was not modeled in either FE models since qCTscan and X-ray images are not precise enough to measure cortical thickness with pixel sizes being larger than average cortical thickness in a vertebra. The contribution of the cortical shell to vertebral strength is not well established in the literature with cortical shell accounting from $10 \%$ to $75 \%$ for vertebral strength (Roux et al., 2010; Rockoff et al., 1969; Andresen et al., 1998; McBroom et al., 1985). However trabecular bone appears to play the primary role in determining vertebral body strength (Silva et al., 1997; Hulme et al., 2007; Perilli et al., 2012; Fields et al., 2009). Other limitations are the sample size and the cadaveric nature of the vertebrae. Twenty-eight vertebrae is a reasonable number when looking at correlation however the vertebrae were extracted from 11 donors which makes the data not truly independent. Pseudo-replication was accounted by calculating an adjusted $\mathrm{R}^{2}$ coefficient using the average data for each donor. However 11 data points was not enough for correlation analysis and underpowered the study. Given the purpose of the present study is to compare the performance from different modalities in predicting experimental vertebral strength, and therefore using a repeated between-vertebrae design, pseudo-replication should not be a significant issue.

Further limitations are the in vitro nature of the study which might not be representative to in vivo situation. Therefore these results cannot be directly extrapolated into in vivo condition and future work should assess the performance of the BP2E-based FE model in discriminating patients with and without vertebral fracture. Moreover, the loading conditions applied on the vertebrae were designed to replicate anterior wedge-shape fractures but they were not fully representative of in vivo loading conditions as adjacent vertebrae and intervertebral disc are major factors to vertebral fractures. Another advantage in using biplanar X-rays in erect position is to consider patient-specific loading condition in vivo and therefore taking into account the patient's posture.

\section{Conclusion}

In conclusion in this in vitro study of lumbar vertebral bodies, it was shown that vertebral strength determined from FE models are strong predictors of experimental failure load, highlighting the capability of bi-planar dual energy (BP2E) X-rays absorptiometry based FE model to predict vertebral body strength. BP2E X-ray absorptiometry allows for fast, low-radiation and minimal cost patient-specific 3D FE model as accurate as qCT-based FE models, currently the gold standard for vertebral strength prediction. These findings support further exploration of the clinical application of BP2E-based FE models in vertebral fracture prediction.

\section{Acknowledgment}

The authors would like to thank S. Persohn and M. Jeyasankar for contributing to mechanical testing. The authors would also thank Anabela Darbon, advanced research engineer at EOS Imaging, for EOS ${ }^{\circledR}$ dual energy acquisition and calibration. This work was supported by the Banque Publique d'Investissement through the dexEOS project part of the FUI14. The funding agencies had no role in the design and conduct of the study, in the collection, management, analysis and interpretation of the data, or in the preparation, review, or approval of the manuscript.

\section{Authors'roles}

Study design: JC, JMV and WS. Study conduct: JC, JMV, CT, SK, CR and WS. Data collection: JC, JMV and SK. Data analysis: JC, JMV and WS. Data interpretation: JC, SK, CT, CR and WS. Drafting manuscript: JC and WS. Revising manuscript content: JC, JMV, CT, SK, CR and WS. Approval final version of manuscript: JC, JMV, CT, SK, CR and WS. WS takes responsibility for the integrity of the data analysis.

\section{Conflict of interest}

The authors have no conflict of interest to declare. Wafa Skalli is the co-inventor of the EOS system without direct financial interest.

\section{References}

Ahmad, O., et al., 2010. Volumetric DXA (VXA): a new method to extract 3D information from multiple in vivo DXA images. J. Bone Miner. Res. 25 (12), 2744-2751.

Andresen, R., Werner, H.J., Schober, H.C., 1998. Contribution of the cortical shell of vertebrae to mechanical behaviour of the lumbar vertebrae with implications for predicting fracture risk. Br. J. Radiol. 71, 759-765.

Assessment of fracture risk and its application to screening for postmenopausal osteoporosis. Report of a WHO Study Group. World Health Organization technical report series, 1994. 843: p. 1-129.

Briot, K., et al., 2015. Diagnosis of vertebral fractures using a low-dose biplanar imaging system. Osteoporos. Int. 26 (11), 2649-2655.

Buckley, J.M., Loo, K., Motherway, J., 2007. Comparison of quantitative computed tomography-based measures in predicting vertebral compressive strength. Bone 40 (3), 767-774.

Chevalier, Y., et al., 2008. A patient-specific finite element methodology to predict damage accumulation in vertebral bodies under axial compression, sagittal flexion and combined loads. Comput. Methods Biomech. Biomed. Eng. 11 (5), 477-487.

Chevalier, Y., et al., 2010. Biomechanical effects of teriparatide in women with osteoporosis treated previously with alendronate and risedronate: results from quantitative computed tomography-based finite element analysis of the vertebral body. Bone 46 (1), 41-48.

Choisne, J., et al., 2017. A new method to determine volumetric bone mineral density from bi-planar dual energy radiographs using a finite element model: an ex-vivo study. J. Musculoskelet. Res. 20 (03), 1750003.

Crawford, R.P., Cann, C.E., Keaveny, T.M., 2003. Finite element models predict in vitro vertebral body compressive strength better than quantitative computed tomography. Bone 33 (4), 744-750.

Dall'Ara, E., et al., 2010. A nonlinear finite element model validation study based on a novel experimental technique for inducing anterior wedge-shape fractures in human vertebral bodies in vitro. J. Biomech. 43 (12), 2374-2380.

Damet, J., et al., 2014. Occupational and patient exposure as well as image quality for full spine examinations with the EOS imaging system. Med. Phys. 41, 6.

Dubousset, J., et al., 2010. EOS: a new imaging system WITH low dose radiation IN 
standing position FOR spine AND bone \& joint disorders. J. Musculoskelet. Res. 13 (01), 1-12.

Ebbesen, E.N., et al., 1999. Lumbar vertebral body compressive strength evaluated by dual-energy X-ray absorptiometry, quantitative computed tomography, and ashing. Bone 25 (6), 713-724.

Edmondston, S.J., et al., 1997. Ex vivo estimation of thoracolumbar vertebral body compressive strength: the relative contributions of bone densitometry and vertebral morphometry. Osteoporos. Int. 7 (2), 142-148.

Eriksson, S.A.V., Isberg, B.O., Lindgren, J.U., 1989. Prediction of vertebral strength by dual photon absorptiometry and quantitative computed tomography. Calcif. Tissue Int. 44 (4), 243-250.

Faulkner, K.G., Cann, C.E., Hasegawa, B.H., 1991. Effect of bone distribution on vertebral strength: assessment with patient-specific nonlinear finite element analysis. Radiology 179 (3), 669-674.

Fields, A.J., et al., 2009. Role of trabecular microarchitecture in whole-vertebral body biomechanical behavior. J. Bone Mineral. Res. 24 (9), 1523-1530.

Grosland, N.M., et al., 2009. IA-FEMesh: an open-source, interactive, multiblock approach to anatomic finite element model development. Comput. Methods Prog. Biomed. 94 (1), 96-107.

Hulme, P.A., Boyd, S.K., Ferguson, S.J., 2007. Regional variation in vertebral bone morphology and its contribution to vertebral fracture strength. Bone 41 (6), 946-957.

Humbert, L., et al., 2009. 3D reconstruction of the spine from biplanar X-rays using parametric models based on transversal and longitudinal inferences. Med. Eng. Phys. 31 (6), 681-687.

Imai, K., et al., 2006. Nonlinear finite element model predicts vertebral bone strength and fracture site. Spine 31 (16), 1789-1794.

Kanis, J.A., et al., 2013. European guidance for the diagnosis and management of osteoporosis in postmenopausal women. Osteoporos. Int. 24 (1), 23-57.

Kanis, J.A., Johnell, O., 2005. Requirements for DXA for the management of osteoporosis in Europe. Osteoporos. Int 16 (3), 229-238.

Kanis, J.A., McCloskey, E.V., 1992. Epidemiology of vertebral osteoporosis. Bone 13 (SUPPL. 2), S1-S10.

Keaveny, T.M., et al., 2007. Effects of teriparatide and alendronate on vertebral strength as assessed by finite element modeling of QCT scans in women with osteoporosis. J. Bone Mineral. Res. 22 (1), 149-157.

Kopperdahl, D.L., et al., 2014. Assessment of incident spine and hip fractures in women and men using finite element analysis of CT scans. J. Bone Mineral. Res. 29 (3), 570-580.

Le Pennec, G., et al., 2014. CT-based semi-automatic quantification of vertebral fracture restoration. Comput. Methods Biomech. Biomed. Eng. 17 (10), 1086-1095.

Liebschner, M.A., et al., 2003. Finite element modeling of the human thoracolumbar spine. Spine 28 (6), 559-565.

McBroom, R.J., et al., 1985. Prediction of vertebral body compressive fracture using quantitative computed tomography. J. Bone Jt. Surg. Ser. A 67 (8), 1206-1214.
McDonnell, P., McHugh, P.E., O'Mahoney, D., 2007. Vertebral osteoporosis and trabecular bone quality. Ann. Biomed. Eng. 35 (2), 170-189.

Meng, X.L., Rosenthal, R., Rubin, D.B., 1992. Comparing correlated correlation coefficients. Psychol. Bull. 111 (1), 172-175.

Moro, M., et al., 1995. Failure load of thoracic vertebrae correlates with lumbar bone mineral density measured by DXA. Calcif. Tissue Int. 56 (3), 206-209.

Parfitt, A.M., 1987. Trabecular bone architecture in the pathogenesis and prevention of fracture. Am. J. Med. 82 (1 SUPPL. 2), 68-72.

Perilli, E., et al., 2012. Failure strength of human vertebrae: prediction using bone mineral density measured by DXA and bone volume by micro-CT. Bone 50 (6), 1416-1425.

Rockoff, S.D., Sweet, E., Bleustein, J., 1969. The relative contribution of trabecular and cortical bone to the strength of human lumbar vertebrae. Calcif. Tissue Res. 3 (1), $163-175$.

Roux, J.P., et al., 2010. Contribution of trabecular and cortical components to biomechanical behavior of human vertebrae: an ex vivo study. J. Bone Mineral. Res. 25 (2), 356-361.

Sapin, E., et al., 2008. Bone mineral density assessment using the EOS low-dose X-ray device: a feasibility study. Proc. Inst. Mech. Eng. H 222 (8), 1263-1271.

Sapin-De Brosses, E., et al., 2012. Prediction of the vertebral strength using a finite element model derived from low-dose biplanar imaging: benefits of subject-specific material properties. Spine 37 (3), E156-E162.

Seeley, D.G., et al., 1992. Which fractures are associated with low appendicular bone mass in elderly women? Obstet. Gynecol. Surv. 47 (6), 424-425.

Silva, M.J., Keaveny, T.M., Hayes, W.C., 1997. Load sharing between the shell and centrum in the lumbar vertebral body. Spine 22 (2), 140-150.

Singer, K., et al., 1995. Prediction of thoracic and lumbar vertebral body compressive strength: correlations with bone mineral density and vertebral region. Bone 17 (2), $167-174$.

Sornay-Rendu, E., et al., 2005. Identification of osteopenic women at high risk of fracture: the OFELY study. J. Bone Miner. Res. 20 (10), 1813-1819.

Travert, C., et al., 2013. 3D-XA-based vertebral finite element model for strength Evaluation in osteoporosis. J. Bone Miner. Res. 28 (Suppl 1).

Wadsworth, T.G., 1990. Colles' fracture. failure in management may cause permanent disability. Br. Med. J. 301 (6745), 192-194.

Wang, X., et al., 2012. Prediction of new clinical vertebral fractures in elderly men using finite element analysis of CT scans. J. Bone Miner. Res. 27 (4), 808-816.

Whitmarsh, T., et al., 2011. Reconstructing the 3D shape and bone mineral density distribution of the proximal femur from dual-energy X-ray absorptiometry. IEEE Trans. Med. Imaging 30 (12), 2101-2114.

Whitmarsh, T., et al., 2013. 3D reconstruction of the lumbar vertebrae from anteroposterior and lateral dual-energy X-ray absorptiometry. Med. Image Anal. 17 (4), 475-487. 